\title{
Shifting Roles of Predisposing Agents, Spatial Contagion, And Accessible Host Quality Drive Phase Transitions of An Irruptive Herbivore
}

Michael Howe ( $\nabla$ howe3@wisc.edu)

University of Wisconsin-Madison https://orcid.org/0000-0002-9694-0835

Kenneth F Raffa

University of Wisconsin-Madison

Brian Aukema

University of Minnesota

Claudio Gratton

University of Wisconsin-Madison

Allan Carroll

The University of British Columbia Faculty of Forestry

\section{Research Article}

Keywords: Bark Beetles, Population Dynamics, Density-Dependence, Phase Transitions, Feedbacks

Posted Date: August 30th, 2021

DOI: https://doi.org/10.21203/rs.3.rs-777227/v1

License: (c) (1) This work is licensed under a Creative Commons Attribution 4.0 International License. Read Full License 
1 Shifting roles of predisposing agents, spatial contagion, and accessible host quality drive

2 phase transitions of an irruptive insect herbivore

3 Michael Howe $^{1}$, Kenneth F. Raffa ${ }^{1}$, Brian Aukema ${ }^{2}$, Claudio Gratton $^{1}$ and Allan Carroll ${ }^{3 \#}$

4 1. Department of Entomology, University of Wisconsin-Madison, Madison, WI 53706, USA

5 2. Department of Entomology, University of Minnesota, St. Paul, MN 55108, USA.

6 3. Department of Forestry, University of British Columbia, Vancouver, BC V6T 1Z4, Canada

$7 \quad$ \#Address correspondence:

$8 \quad$ Allan Carroll

$9 \quad$ allan.carroll@ubc.ca

10 Keywords: Bark Beetles, Population Dynamics, Density-Dependence, Phase Transitions,

11 Feedbacks.

12

13 Author Contributions:

14 AC conceived, designed, and performed the experiment. $\mathrm{MH}$ analyzed the data. $\mathrm{MH}, \mathrm{KR}, \mathrm{BA}$, $15 \mathrm{CG}$ and $\mathrm{AC}$ wrote the manuscript.

16

17 Target Journal: Oecologia (10 page limit: $\sim 35$ pages submitted).

18 


\section{Abstract - 250 Limit (249 currently)}

Irruptive forest insects such as bark beetles undergo intermittent outbreaks that cause

21 landscape-scale tree mortality. Despite their enormous economic and ecological impacts we still

22 have only limited understanding of the dynamics by which populations transition from normally

23 stable endemic to irruptive densities. We investigated density-dependent changes in mountain

24 pine beetle reliance on stressed hosts, host selection, spatial configuration of attacks, and the

25 interaction of host selection and spatial configuration by performing a complete census of

26 lodgepole pine across six stands and six years. Additionally, we compared the dynamics of

27 mountain pine beetle with those of other bark beetles. We found that as population size

28 increased, reliance on stressed trees decreased and new attacks shifted to larger trees with thicker

29 phloem and higher growth rates that can support higher offspring production. Moreover, the

30 spatial configuration of beetle-attacked trees shifted from random to spatially aggregated.

31 Further, we found evidence that beetle utilization of larger trees was related to aggregation

32 behavior as the size of tree attacked was positively correlated at 10-25 $\mathrm{m}$, within the effective

33 distance of pheromone-mediated signaling. In contrast, non-irruptive bark beetle species did not

34 exhibit such density-dependent spatial aggregation at the stand scale or switches in host selection

35 behavior. These results identify how density-dependent linkages between spatial configuration

36 and host utilization can converge to drive population transitions from endemic to irruptive

37 phases. Specifically, a combination of stand-level spatial aggregation, behavioral shifts, and

38 higher quality of attainable hosts defines a critical threshold beyond which continual population 39 growth becomes self-driving. 


\section{Introduction}

Irruptive insect herbivores cause significant tree mortality globally (Peltonen et al. 2002;

43 Anderegg et al. 2015; Hicke et al. 2016) and can ultimately lead to pervasive shifts in ecosystem

44 dynamics and services (McDowell et al. 2020). Population fluxes of forest insects are integral

45 components of disturbance regimes and can promote heterogeneity (Turner et al. 2004),

46 biodiversity (Beudert et al. 2015), and ecosystem services (Thom and Seidl 2016). Yet, several

47 recent largescale outbreaks coupled with warming temperatures and severe droughts have caused

48 unprecedented tree mortality in historically impacted and relatively novel locations (Williams

49 and Liebhold 2006; Jepsen et al. 2008; Allen et al. 2015; Seidl et al. 2017). These shifting

50 regimes have led to substantial economic and environmental losses (Kurz et al. 2008; Hicke et al.

51 2012; Chang et al. 2012; Seidl et al. 2015). Both the frequency and severity of irruptions by

52 some native species are increasing due to climate change and land use alteration (Ayres and

53 Lombardero 2000; Seidl et al. 2017; Biedermann et al. 2019).

Outbreaks of forest insects can occur in periodic intervals (Royama 1992; Berryman

55 1996; Kendall et al. 1999; Bjornstad and Grenfell 2001) or intermittently in response to pulses of

56 resource availability or bioclimatic suitability (Powers et al. 1999; Aukema et al. 2006; Økland

57 and Bjørnstad 2006). The likelihood and extent of irruptions are often mediated by competing

58 negative and positive feedbacks (Berryman 1987; Raffa et al. 2008; Biedermann et al. 2019).

59 Negative feedbacks include resource depletion (Økland and Berryman 2004; Økland and

60 Bjørnstad 2006), host defenses (Boone et al. 2011, Howe et al. 2020), and natural enemies

61 (Turchin 1999; Dwyer et al. 2004; Cobbold et al. 2009). Positive feedbacks include cooperative

62 host utilization, predator escape, and improved mate finding (Larsson et al. 2000, Liebhold and 
63 Tobin 2008, Kausrud et al. 2012). Once populations transition past crucial thresholds positive

64 feedbacks can become dominant and generate self-driving population growth (Berryman 1987).

Despite our extensive knowledge of the basic biology and emergent landscape patterns of

66 irruptive forest insects, relatively little is known about the processes by which they transition

67 from their endemic to irruptive phases. For example, we do not have a good understanding of

68 how the spatial dynamics of infestation trees within a stand interact with host selection behavior,

69 tree defenses, and endogenous drivers. Consequently, models that examine the dynamics of

70 outbreak spread are not timely for applying effective mitigation measures.

71 The most destructive forest insects worldwide are bark beetles that colonize the

72 subcortical tissues of the main stems of conifers. Bark beetle species that colonize live tree stems

73 can be broadly grouped into three groups, those that colonize lower-stems and are functionally

74 parasitic in that they don't typically kill trees (lower-stem hereafter) (Gregoire 1985), irrupt in

75 response to a pulse of resources (pulse-driven hereafter) (Øklund and Bjørnstad 2006, Aukema et

76 al. 2016), or breach cross-scalar thresholds to undergo self-driving growth (threshold-limited

77 hereafter) (Berryman 1987, Raffa et al. 2008). Irruptive bark beetles (i.e., those that are pulse-

78 driven or threshold-limited) exhibit long endemic phases during which populations are low and

79 colonize trees that are either dead or highly stressed. Such hosts are poorly defended but also

80 nutritionally sub-optimal. This endemic phase can be followed by rapid transitions from incipient

81 to epidemic phases (Safranyik and Carroll 2006). Lower-stem bark beetles generally do not

82 undergo outbreaks, except in rare cases where they are introduced to new regions (Yan et al.

83 2004). At the landscape-scale, population transitions of irruptive bark beetles are often

84 synchronous across large areas and driven by high temperatures and drought (Aukema et al.

85 2008; Marini et al. 2012; Preisler et al. 2012; Kolb 2016; Seidl et al. 2016; Hart et al. 2017; 
86 Sommerfeld et al. 2018). At the stand scale, population increases can be driven by increasing tree

87 age, biotic and abiotic stressors, and high tree density. Mountain pine beetle (Dendroctonus ponderosae Hopkins) occurs throughout western

89 North America. It is most closely associated with lodgepole pine (Pinus contorta Douglas), but can utilize most Pinus spp. in its range (Meddens et al. 2012). Successful colonization causes

91 tree mortality within one to two years, and beetles can usually reproduce in a tree for only one 92 generation (Safranyik and Carroll 2006). Brood production is directly related to tree diameter 93 and phloem thickness (Amman and Cole 1983, Safranyik and Carroll 2006). Pines possess 94 sophisticated multimodal defenses that can usually resist attacks, often resulting in attack 95 abandonment or beetle mortality (Raffa et al. 2005). Beetles can avoid these defenses by entering 96 only highly stressed trees during lengthy low-density periods. Alternatively, beetles can 97 overcome trees of almost any vigor class once their populations are high (Waring and Pitman 98 1985, Boone et al. 2011, Williams et al. 2018). The ability of large populations to utilize healthy 99 trees is driven by pheromone-mediated mass attacks by which high numbers of beetles can 100 overcome otherwise efficacious defenses (Raffa and Berryman 1983, Blomquist et al. 2010). 101 Low populations are typically unable to elicit mass attacks. The population dynamics, attack behavior, and spatial spread of epidemic mountain pine 103 beetle populations are relatively well described (Aukema et al. 2006; Preisler et al. 2012; Cooke 104 and Carroll 2017). However, the critical transition from the endemic to irruptive phase remains 105 understudied for several reasons. First the broad scale of these ecosystems necessitates extensive 106 aerial surveys for monitoring and surveillance, but aerial surveys primarily detect tree mortality 107 where populations have already transitioned past the endemic phase. Second, despite the 108 importance of external landscape scale drivers such as climate, population transitions occur at the 
stand level. Furthermore, local drivers, such as biotic agents that impair tree defenses are not necessarily detectable or manifested at large spatial scales. Third, the transition from net negative

111 feedback, where population growth is limited to low-vigor trees and below thresholds needed to

112 overcome vigorous trees, to positive feedback (self-sustaining population growth) can occur

113 rapidly, further complicating attempts to capture dynamics at either the landscape or stand scales.

114 Although there is substantial information on how certain agents impair host defenses at

115 the tree level, we have little understanding of how prior stressors, beetle attack behavior, and

116 host availability interact to either constrain endemic populations or foster phase transitions. Prior

117 work suggests potential variation in the clustering of attacks (Safranyik and Carroll 2006;

118 Bleiker et al. 2014), and that lower-stem colonizing bark beetle species or mistletoe (Klutsch et

119 al. 2014) may create a low-vigor niche for endemic mountain pine beetle populations (Smith et

120 al. 2011). However, few studies have attempted to integrate the spatial and mechanistic

121 components of endemic-irruptive phase transitions (Koopmans 2011).

122

Our objective was to explore four facets of an irruptive herbivore's stand and tree level

123 interactions that putatively tilt net feedbacks from negative to positive and hence initiate

124 outbreaks. Specifically, we test whether: a) beetle reliance on prior stress agents, b) host

125 utilization, c) spatial distribution of attacks, and d) the interaction of spatial distribution of

126 attacks and size of attacked trees changes with local population density. Further, we compare

127 these threshold-limited attack dynamics and interactions with pulse-driven, and lower-stem bark

128 beetles in the same system. We hypothesize that behavioral shifts putatively concentrate beetle 129 populations so as to maximize the likelihood of success of pheromone-mediated mass attacks,

130 allow beetles to overcome defenses of previously inaccessible vigorous trees, and utilize

131 nutritionally high-quality trees that enhance brood production. 


\section{Methods}

\section{Site Establishment}

135 Six mature lodgepole pine (Pinus contorta Douglas) stands at two sites (Angstad Creek, 136 Aberdeen Plateau) in southern British Columbia were randomly selected to monitor beetle 137 populations for 3-6 years (Boone et al. 2011). Candidate stands were first identified from forest 138 inventory maps (forest inventory methods [link]) and were considered for study if they: 1) were 139 located within areas of historically suitable climate for mountain pine beetle (Safranyik and 140 Carroll 2006; Safranyik et al. 2010); 2) contained no mountain pine beetle activity observable

141 from aerial surveys (aerial survey methods [link]) but did have endemic reproducing populations

142 verified by on-site observations; 3) were at least $10 \mathrm{~km}$ away from recorded tree mortality caused

143 by epidemic mountain pine beetle; and 4) were at least $1 \mathrm{~km}$ away from each other. Stands A and

144 B were established in 2000, stands D and E in 2001, stand F in 2002, and stand G in 2003.

145 Stands A, B, and F were located at Angstad Creek and stands D, E, and G were located on the 146 Aberdeen Plateau (Figure 1).

147 Variable radius plots (Avery and Burkhart 2002) were installed in each stand at a density

148 of 1 plot/ha and mensurational characteristics were quantified. The stands averaged 15.3 ha, with 1491265 trees/ha, and were comprised of 90.3\% lodgepole pine. The average age of lodgepole pines 150 was approximately 100 years, the mean basal area was $40.75 \mathrm{~m}^{2} / \mathrm{ha}$, and the mean diameter at 151 breast height (DBH) was $22.65 \mathrm{~cm}$ (Boone et al. 2011).

152 Site Monitoring

153 For the duration of the study (2000-2005), presence/absence of bark beetle attack was 154 assessed for every tree within the stands (an estimated 110,000 trees). At each site, a $25 \times 50 \mathrm{~m}$ 
155 grid was established as a reference and the stems of all trees were assessed for evidence of attack 156 (Carroll et al. 2006). All trees within a stand were censused at four-week intervals from June-

157 September. All trees were censused for evidence of beetle attack, and upon confirmation of 158 attack, were spatially referenced and their characteristics and condition were assessed. Potential 159 conditions that could impair tree vigor (e.g. physical damage, root or foliar infections, etc.) were 160 recorded (Supplemental Table 1). For every attacked tree, a small amount of bark was removed $161\left(<225 \mathrm{~cm}^{2} /\right.$ tree $)$ to confirm beetle activity and species identification. For trees in which some or 162 all beetles had completed development and dispersed, the timing of attack (i.e., year) was 163 estimated based on condition of the phloem, presence of subcortical beetles, and the condition of 164 remaining foliage (Supplemental Table 2) (Carroll et al. 2006). DBH was measured for each 165 attacked tree $(n=5287)$ while mean annual increments at 5 years $(n=2320)$, phloem thickness $166(n=834)$, and tree height $(n=2589)$, were measured for a subsample of trees.

167 For the purposes of these analyses, we separated bark beetles into three guilds: threshold168 limited species, i.e., mountain pine beetle ( $n=5,320$ attacked trees); pulse-driven species, i.e., Ips 169 pini Say ( $n=140$ attacked trees); and lower-stem bark beetle species that included $D$. murrayanae 170 Hopkins ( $n=206$ attacked trees), D. valens LeConte ( $n=35$ attacked trees), Hylurgops spp. ( $H$.

171 porosus LeConte \& H. rugipennis Mannerheim; $n=478$ attacked trees), Orthotomicus latidens

172 LeConte ( $n=1099$ attacked trees), and Pseudips mexicanus Hopkins ( $n=1906$ attacked trees).

173 Further, in lieu of definitive counts of beetle population size, we assume that the number of 174 attacked trees/ha is highly correlated with local population size since a complete census of 175 beetles is not possible.

$176 \quad$ Non-baited flight intercept panel traps (Schmitz 1984) were placed at regular intervals (8177 18/site) in each stand and checked approximately every ten days from late May until September 
178 during the above years. Because total trap catch numbers over the course of the study were low

179 (257 mountain pine beetles, 102 Ips pini, and 953 lower-stem bark beetles), a common problem

180 when sampling endemic populations without pheromones (Krause et al. 2018), these data were

181 not incorporated into analyses.

182 Analyses

183 All data wrangling and analyses were conducted in R (4.0.2) using R Studio (1.3.1073).

184 The relevant R packages include: tidyverse for wrangling and visualizations (Hadley et al. 2019);

185 sf for plotting spatial data with ggplot (Pebesma 2018); spatstat for examining point process

186 models (Baddeley et al. 2015); ggeffects for visualizing predicted least squares fits for

187 interactions (Ludecke 2018), vegan for multivariate analyses (Oksanen et al. 2020), and

188 factoMiner/factoextra for visualizing multivariate analyses (Kassambara and Mundt 2020).

189 Are there density dependent shifts in beetle reliance on prior stressors?

190 Beetle reliance on prior stressors as a function of population size was analyzed using

191 linear and generalized linear models. Linear models were used to compare the proportion of

192 trees/stand with either prior or no prior stressors (e.g. mistletoe, physical deformities, lower-stem

193 bark beetle attack; Supplemental Table 1) with a covariate of $\log _{10}($ number of attacked trees/ha).

194 Generalized linear models (with logit link function) were used to compare the likelihood that an

195 attacked tree had either a prior stressor ("1") or no prior stressor ("0"), with a covariate of

$196 \log _{10}($ number of attacked trees/ha). Thus, linear models were conducted on a per-stand basis

197 while generalized linear models were conducted with a response on a per-tree basis and a

198 predictor on a per-stand basis. The appropriateness of each model was assessed graphically. The

199 apparent breakpoint in the sigmoidal relationship between the probability an attacked tree had a 
200 prior stressor and population density for threshold-limited bark beetles (Figure 2D) is due to the 201 properties of log-transformed values below and above 1.

203 Are there density dependent shifts in host utilization?

204 Changes in beetle host utilization (e.g., beetles attacking larger trees) as a function of 205 population size were analyzed for each guild using linear models. Three linear models were fit 206 with responses of: $\mathrm{DBH}, 5$-year mean annual increment, and phloem thickness, with a covariate 207 of the $\log _{10}$ (number of attacked trees/ha). Model assumptions were assessed graphically for all 208 model fits. The residuals from linear model constructed for 5-year mean annual growth 209 increment exhibited a fair amount of heteroscedasticity and were not normally distributed.

210 However, in our analyses, heteroscedasticity is largely due to the uneven sampling scheme (i.e.

211 larger values of $\mathrm{x}$ have more observations) and no simple transformations easily fixed the

212 residuals, so we report the original non-transformed linear models. Relationships between host 213 selection by each bark beetle guild and tree characteristics including prior injury or disease, tree

214 height, DBH, 5-year mean annual increment, phloem thickness, and population size, was 215 explored using principal components analysis (PCA). Hypothesis testing was performed using

216 permutational multivariate analysis of variance (PERMANOVA), with Bray-Curtis as the

217 distance metric. Screeplots are provided in Supplemental Figure 1.

219 Are there density dependent shifts in the spatial configuration of attacked trees?

220 The spatiotemporal dynamics of bark beetle attacks were assessed both graphically (i.e.,

221 x-y plots for each stand/year) and by describing the distribution of attacked trees with a

222 transformed Ripley's K-function (L-function hereafter). More specifically, we tested whether the 
223 distribution of attacked trees was more aggregated (positive spatial correlation) or inhibited

224 (negative spatial correlation) than random. Further, we did not assume that there was an equal

225 chance of observing a beetle attack throughout our observation window because each censused

226 area was embedded within a larger stand to diminish possible edge effects (Carroll et al. 2006)

227 and the spatial distribution of tree size was likely not homogenous (see for example, Matasci et

228 al. 2018, for within stand variability of lodgepole pine basal area at $30 \mathrm{~m}^{2}$ across BC). As a

229 result, all L-functions were fit with an inhomogeneous process.

230 Hypothesis testing for each stand/year was conducted through the following process.

231 First, duplicate attacks (i.e., trees attacked by multiple bark beetles of the same guild) were

232 removed (threshold-limited: $\max .=2$; pulse-driven: $\max .=2$; lower-stem: $\max .=6$ ). Next, we

233 created a realization of the joint density of all trees attacked by bark beetles. Originally, separate

234 densities were fit for each 'marked' point (i.e., each guild of beetle), but since the significance

235 bands were not visually distinguishable from the joint density significance bands, the joint

236 density was used for ease of processing and because we are operating under the assumption that

237 trees within a stand are equally likely to be attacked by beetles from each guild. Joint densities

238 were realized with smoothing parameters of $\sigma=50, \sigma=15$, and $\sigma=5$ that correspond to null

239 hypotheses of the underlying spatial distribution of available low-vigor trees. Significance bands

240 were calculated by simulating 999 realizations of an inhomogeneous Poisson process based on

241 each realized joint density. We then compared the observed L-function to the simulated

242 significance bands. Portions of each observed L-function higher or lower than the significance

243 bands were significantly ( $\mathrm{p}$-value $<0.001$ ) more aggregated or inhibited than random. We

244 provide a step-by-step walkthrough of this process in Supplemental Figure 2. Further, we

245 supplemented our graphical interpretation of each point pattern using a nearest neighbor 
246 approach, the Clark-Evans aggregation index (Clark and Evans 1954), with 999 simulations

247 (Supplemental Figure 3).

249 Are there interactions between size of tree attacked and spatial configuration of attacks?

250 Spatial correlation of size of tree attacked was analyzed by fitting a conditional mean

251 summary function, E(r), for each stand (Schlather et al. 2004). This approach allowed us to test

252 the spatial correlation of a continuous 'marked' point pattern (conceptually similar to a

253 semivariogram). Significance was assessed with an envelope with 999 simulations. E-functions

254 were fit using attacks from all bark beetles since the function behaves better when points are

255 approximately evenly spaced. The summary function for stand B was fit based on attacks from

256 1999-2003, since we were primarily interested in describing the spatial dependence of the early

257 stages of aggregation and not stand-level irruption.

258

259 Results

Overall, from 1999-2005 we observed 9204 trees attacked by bark beetles, 58\% of which

261 were attacked by mountain pine beetle ( $\mathrm{n}=5340$ trees), $2 \%$ by Ips ( $\mathrm{n}=140$ trees), and $40 \%$ by

262 lower-stem bark beetles ( $n=3724$ trees). At the beginning of the time series in 1999, there were

263 only 19 attacked trees, and by 2005 there were 3411 . The number of trees attacked by each guild

264 varied substantially among and within stands over time (Table 1).

265

266

Density-dependent shifts in mountain pine beetle dependence on prior stress agents

Mountain pine beetles predominantly attacked trees with prior stressors when their

268 populations were low, but not when their populations were high (Figure 2A; slope=-0.22; 
$269 \mathrm{~F}_{1,29}=9.59 ; \mathrm{p}$-value $\left.=0.004\right)$. The probability that a tree attacked by mountain pine beetle had a

270 prior stressor decreased as the beetle population size increased (Figure 2D; odds ratio $=0.01$;

$271 \chi_{(1)}^{2}=1224.96 ; \mathrm{p}$-value $\left.<0.001\right)$. That is, likelihood odds that an attacked tree had a prior stressor

272 decreased by 0.99 for each ten-fold increase in the number of attacked trees/ha. From 1999-2005,

$27320 \%$ of trees attacked by mountain pine beetle ( $70 \%$ if Stand B in 2005 is removed) had prior

274 stressors.

275

276 Density-dependent shifts in size, growth rates, and phloem thickness of trees attacked by

277 mountain pine beetles

278 As mountain pine beetle populations increased, beetles attacked larger trees (Figure 3A;

279 slope $=1.37, \mathrm{~F}_{1,5652}=119.3 ; \mathrm{p}$-value $<0.001$ ); however, there was substantial unexplained

280 variability $\left(\mathrm{R}^{2}=0.02\right)$. Likewise, at higher populations mountain pine beetles attacked trees with

281 higher growth rates (Figure 3B; slope $=0.21 ; \mathrm{F}_{1,2349}=242.6$; $\mathrm{p}$-value $<0.001$ ), which explained

$282 \sim 10 \%$ of the observed variability $\left(\mathrm{R}^{2}\right)$. Additionally, at higher populations, mountain pine beetle

283 attacked trees with thicker phloem (Figure 3C; slope $=0.74 ; \mathrm{F}_{1,880}=145.7 ; \mathrm{p}$-value $<0.001$ ), which

284 explained the greatest amount of variability $\left(\mathrm{R}^{2}=0.14\right)$, although this sample size was smaller.

285 Population size did not affect height of trees attacked $\left(\mathrm{F}_{1,2686}=3.8 ; \mathrm{p}\right.$-value $\left.=0.051\right)$. In total, these

286 density-dependent shifts in host selection were associated with beetles attacking trees that were

287 on average, larger, with faster growth rates, and with thicker phloem (Figure 3D;

288 PERMANOVA; $\mathrm{F}_{2,2291}=172.82 ; \mathrm{p}$-value $<0.001$ ). However, these characteristics explained little 289 of the observed variability attributable to differences among bark beetle guilds $\left(\mathrm{R}^{2}=0.1\right)$ and was 290 better explained by among-site differences $\left(\mathrm{R}^{2}=0.26\right)$. 
294 of six stands and shifted from putatively random to aggregated (Figure 4A; stands A, B, \& F).

295 Changes in spatial distribution were not apparent in two stands (Figure 4B; stands D \& G) or in 296 the case of stand E, were not likely a result of within-stand dynamics (Figure 4B) (Carroll et al.

297 2006). In stands $A, B$, and $F$, the spatial pattern of trees attacked by mountain pine beetle shifted 298 from no spatial structure to significant positive spatial correlation (i.e., aggregation; p-value < 299 0.001) as mountain pine beetle populations increased (interpretation of the observed L(r)-r 300 functions for each stand-year: Figure 5; all observed L(r)-r functions: Supplemental Table 3).

301 Moreover, the shift from random to aggregated attacks appeared to occur between 2 and 4 302 attacked trees/ha (Figure 5; grey box). In stand A, the pattern of attacked trees at the beginning 303 of the spatial transition (2001-2003) also exhibited significant negative spatial correlation (i.e., 304 inhibition) at $\sim 50 \mathrm{~m}$. There was weak evidence of similar patterns in B-2001 and D-2003. As 305 populations continued to increase, there was no significant spatial inhibition. This pattern 306 indicated that during the beginning of the transition from random to aggregated, mountain pine 307 beetles attacked trees in discrete clusters, while at higher population levels, mountain pine beetle 308 attacks did not occur in discrete clusters and were more evenly distributed throughout the stand.

Interactions between the spatial pattern and characteristics of attacked trees

311 Size of trees attacked by mountain pine beetles exhibited significant positive spatial 312 correlation in all of the stands where the distribution of beetle attacks shifted from putatively

313 random to aggregated. In stands A, B, and F, tree size attacked was significantly positively 314 correlated at distances of 5-25 m, and corresponded to beetles attacking trees that were $1-2 \mathrm{~cm}$ 
315 larger than the stand average (Figure 6). Additionally, there was further significant positive

316 correlation around $50 \mathrm{~m}$ in stands $\mathrm{A}$ and $\mathrm{B}$, while there was significant negative correlation

317 around $50 \mathrm{~m}$ in stand $\mathrm{F}$.

318

Density dependent relationships in reliance on prior stressors, host utilization, and spatial

320 aggregation for pulse-driven and lower-stem bark beetles

321

Pulse-driven and lower-stem bark beetles exhibited different dynamics than mountain

322 pine beetle. Although, pulse-driven beetles (i.e., I. pini) exhibited a similar decreasing

323 relationship between population size and reliance on prior stressors (Figure $2 \mathrm{~B}$; slope=-0.18;

$324 \mathrm{~F}_{1,22}=4.5 ; \mathrm{p}$-value $\left.=0.045\right)$, there was no relationship between population size and the probability

325 that an attacked tree had a prior stressor (Figure $2 \mathrm{E} ; \chi_{(1)}^{2}=0.97$; p-value $=0.34$ ). Lower-stem bark

326 beetles always preferred stressed trees and increasing population size was positively related to

327 prior stressors (Figure $2 \mathrm{C}$; slope $=0.20 ; \mathrm{F}_{1,30}=10.96 ; \mathrm{p}$-value $=0.002$ ). Correspondingly, there was

328 no relationship between population size of lower-stem bark beetles, i.e., D. murrayanae, D.,

329 Hylurgops spp. (H. porosus \& H. rugipennis), Orthotomicus latidens, or Pseudips mexicanus,

330 and the probability that an attacked tree had a prior stressor (Figure $2 \mathrm{~F} ; \chi_{(1)}^{2}=0.12 ; \mathrm{p}$-value $=$

331 0.88). Additionally, increasing populations of pulse driven bark beetles attacked smaller trees

332 (Figure $3 \mathrm{~A} ;$ slope $=-2.5 ; \mathrm{F}_{1,204}=6.17 ; \mathrm{p}$-value $\left.=0.01\right)$ and increasing populations of lower-stem

333 bark beetles attacked slower-growing trees (Figure 3B; slope=-0.08; $\mathrm{F}_{1,5414}=94.95$; $\mathrm{p}$ -

334 value $<0.001)$. Pulse-driven bark beetles did not attack faster growing trees or trees with thicker

335 phloem and lower-stem bark beetles did not attack larger trees or those with thicker phloem as

336 population size increased. 
Spatial aggregation dynamics of pulse-driven and lower-stem bark beetles exhibited

338

339

340

341

342

343

344 small patches $(\sim 20-50 \mathrm{~m})$.

\section{Discussion}

Threshold-limited irruptive insect species persist during endemic periods and when

348 appropriate conditions arise transition to an epidemic phase where populations become self-

349 amplifying. For the mountain pine beetle, prior stressors within some host trees provide an

350 endemic niche for sustained reproduction, but reliance on this resource decreases as populations

351 increase. Furthermore, a critical stand-level population threshold exists that separates endemic

352 from incipient/irruptive population phases. The spatial distribution of attacks shifts from random

353 to clustered as aggregation pheromones attract large numbers of beetles that redirect to nearby

354 trees. As their population densities increase, mountain pine beetles begin to colonize larger,

355 thicker-phloemed trees, which yield more offspring (Amman and Cole 1983, Graf et al. 2012),

356 thus driving positive feedback. In contrast, pulse-driven and lower-stem bark beetles did not

357 show density-dependent changes in reliance on prior stressors, host selection, spatial distribution,

358 or their interactions. Jointly, these results underscore the importance of low-vigor trees for the

359 persistence of endemic populations of tree-killing bark beetles, sources of positive feedbacks 
360 driving the onset and expansion of irruptive populations, and key traits differentiating irruptive 361 from nonirruptive species within a closely related taxonomic group.

362 Previous observations and models suggest that the random spatial pattern of attacks at

363 low population densities reflects the similarly relatively random distributions of stressors and

364 susceptible trees within stands (Logan et al. 1998; Powell et al. 1999; Safranyik and Carroll

365 2006; Koopmans 2011). Since colonized trees are usually only available for one beetle

366 generation, they represent a resource pulse that is removed from the pool of available hosts.

367 However, once populations of some bark beetle species are high, they can successfully colonize

368 trees adjacent to those they have filled to capacity (Gara and Coster 1968, Geiszler et al. 1983,

369 Mitchell and Preisler 1991, Preisler and Mitchell 1993). This switching behavior greatly

370 increases beetles' chances of initiating mass attacks on entered trees during outbreaks, but is less

371 likely to succeed when populations are low (Raffa and Berryman 1983; Boone et al. 2011).

372 Switching behavior is mediated by initial attraction to a tunneling beetle in a focal tree by long-

373 range aggregation pheromones (Blomquist et al. 2010) followed by short-range anti-aggregation

374 pheromones that orient beetles to adjacent trees once an optimal attack density is reached (Hunt

375 and Borden 1990; Gitau et al. 2013). The distance of observed significant spatial correlation in

376 this study falls within the effective radius in which this switching behavior occurs (Geiszler and

377 Gara 1978, Geiszler et al. 1980). The likelihood that the beetles maintained by sources of chronic

378 stress on trees can breach the irruptive threshold to cause largescale mortality is influenced by

379 regional bioclimatic conditions, synchrony of neighboring populations, and the availability and

380 connectivity of suitable hosts across the landscape (Peltonen et al. 2002; Logan et al. 2003;

381 Aukema et al. 2006; Safranyik and Carroll 2006; Raffa et al. 2008; Preisler et al. 2012). 
Our results also contribute to our understanding of the relative contributions of stand and regional drivers to population transitions, but disentangling them remains difficult. For example,

384 based on the numeric increases of pulse-driven and lower-stem bark beetles in all stands, the 385 region-wide drought that began in 1999 (SPEI Database) likely increased the availability of low386 vigor trees throughout our study area. This apparent resource-pulse led to mountain pine beetle 387 population phase transitions at Angstad Creek (stands A, B, and F), but not Aberdeen Plateau 388 (increases in stand E likely resulted from of immigration for reasons described earlier). This 389 suggests that either the apparent resource pulses at the Aberdeen Plateau stands were insufficient 390 to support transitions, or perhaps that the large populations of early-season lower-stem beetles in 391 stands D and G outcompeted the late-season mountain pine beetle for food and space within low392 vigor trees (Rankin and Borden 1991; Safranyik et al. 1999) and thus had an overall antagonistic 393 rather than faciliatory effect. Thus, at the landscape-level, it may appear that extreme bioclimatic 394 stressors inevitably lead to population phase transitions, but at the stand-level, such predictions 395 may fail to materialize due to local effects of host-availability or competition.

396 It is well known that mountain pine beetles are associated with large trees during their 397 irruptive phase (Amman 1969, Safranyik and Carroll 2006; Raffa et al. 2008). This association 398 can sometimes be interpreted as a global preference for large trees, and hence that removing 399 large trees can prevent outbreaks. However, we have shown that beetles at endemic densities 400 primarily attack smaller stressed and suppressed trees and only after transitioning past a critical 401 density primarily attacked trees that are larger, have higher growth rates, and contain thicker 402 phloem (Figure 3A-C). Further, the high spatial correlation of attacks on larger trees (Figure 6) 403 highlights the extent to which local aggregation among neighboring trees facilitates changes in 404 host utilization. Our results do not preclude the possibility of an underlying environmental 
405 gradient that may contribute to observed patterns, but the convergence of significant interactions 406 among tree size, aggregation, and decreased reliance on prior stressors at similar distances and 407 population densities makes that explanation less likely. Further, these patterns were only 408 observed in stands where aggregation resulted from within-stand dynamics. Collectively, these 409 observations support a density-dependent model of beetle host selection in which endemic 410 beetles avoid well-defended hosts but epidemic beetles exploit them (Wallin and Raffa 2004; 411 Boone et al. 2011; Powell et al. 2012; Lindgren and Raffa 2013; Burke and Carroll 2017). 412 The interaction of spatial, behavioral, and ecological processes that govern endemic 413 persistence and phase transitions we describe here is generalizable to other tree-killing bark 414 beetles. However, the specific features that structure the endemic niche vary among geographic 415 regions, host-tree, and beetle species. For example, mountain pine beetle endemic populations in 416 some regions are largely maintained in trees affected by wildfire or fungi (Nebeker et al. 1995;

417 Powell et al. 2012). Similarly, endemic populations of southern pine beetle (Dendroctonus 418 frontalis Zimmermann) are maintained largely in lightning-struck trees that are distributed 419 relatively randomly, but subsequent outbreaks show high contagion (Coulson et al. 1983; 420 Martinson et al. 2013). Also, European spruce beetles (Ips typographus L.) disperse over large 421 distances to locate trees downed by storm damage, generating strong Allee effects at low 422 densities, but can transition into outbreaks depending on the amount and spatial configuration of 423 windthrown trees (Liebhold and Tobin 2008; Kausrud et al. 2012). Douglas-fir beetles 424 (Dendroctonus pseudotsugae Hopkins) typically prefer low-vigor or dead hosts (Furniss 1981, 425 Powers et al. 1999; 2016), but increased tree mortality can occur following defoliator outbreaks, 426 again with the scale of beetle outbreaks varying with the dispersal ability and intensity of 427 different defoliator species (Hadley and Veblen 1993; Schaupp et al. 2008; Negron et al. 2014). 
428 In each of these cases, transition from endemic to eruptive phases involves an integration of

429 stand-level biotic or abiotic stressors, largescale region-wide stressors, and plasticity in beetle

430 host selection behavior, with attributes of stand- and landscape- scale stressors and species-

431 specific behavior generating system-specific dynamics (Raffa et al. 2008; Stephenson et al. 2019;

432 Ward and Aukema 2019).

433 For most bark beetle species, system-specific properties preclude the behavioral shift 434 needed to generate self-amplifying dynamics (Raffa et al. 2008). For example, I. pini in this 435 study showed only minor decreases in reliance on prior stressors as its population increased, 436 similar to the minor decreases in reliance on lower stem beetle-fungal complexes it shows in red 437 pine (Pinus resinosa Sol. Ex Aiton) in Wisconsin (Aukema et al. 2010). Likewise, I. grandicollis 438 Eichhoff colonized large numbers of jack pine (Pinus banksiana Lamb.) following defoliation by 439 Choristoneura pinus Freeman, and Ips confusus Wood \& Bright colonized large numbers of 440 pinyon pine (Pinus edulis Engelm.) following drought, but in both cases bark beetle populations 441 subsided when the stress declined (Wallin and Raffa 2001; Raffa et al. 2008).

442 These results have several implications to improved management of bark beetles. First, 443 empirically quantifying the threshold at which populations shift from stress-dependent to self444 driving growth allows managers to target their efforts accordingly. This threshold provides a 445 useful juncture beyond which stand-level management strategies are less likely to contain 446 populations, short of aggressive large-scale sanitizing cuts. Second, identifying related density447 dependent changes in host utilization provides opportunities for proactive management plans 448 such as thinning from below (i.e., removing suppressed trees). Such strategies are likely to be 449 particularly important for preventing outbreaks in large-scale commercial forestry settings.

450 Further, our results provide guidance for the monitoring and modeling of beetle populations. For 
451 example, the critical phase threshold we quantify occurs below or near the density at which tree

452 mortality is likely to be detected by aerial surveys (Cooke and Carroll 2017). Thus, models based

453 on aerial detection data are more useful for understanding the spread of outbreaks rather than

454 factors that drive their onset. Also, unbaited traps did not prove to be useful at low beetle

455 densities. Together these results indicate that integrated aerial, pheromone-based, and ground

456 surveys are required for effective monitoring and management.

457 There are several limitations to our study. First, mensurational data were not collected on

458 all trees or in a sufficiently high-resolution grid, both of which could benefit more formal point

459 process models. Such data could also help partition the extents to which interactions between the

460 size and clustering of attacked trees arise from beetle switching behavior or an underlying

461 environmental gradient. Futher, high-resolution marked point process models with temporal

462 autocorrelation are still in their infancy (Diggle 2013; Badley and Turner 2016). Such models

463 could help account for the temporal dependence among years within the same stand and help

464 disentangle interactions among bark beetle groups.

465 Thresholds and density-dependent feedbacks are critical components of the phase

466 transitions of irruptive insect species (Roffey and Popov 1968). In bark beetle systems, cross-

467 scalar interactions of spatial colonization pattern, host availability, host quality, and herbivore

468 behavior serve as both important inputs and outputs of population dynamics. External drivers

469 such as biotic stressors can add momentum to the system, thus allowing populations to transition

470 between 'quasi-stable' population states (Lindgren and Raffa 2013). These interacting processes

471 merit further investigation to better inform management by improving predictions of when and

472 where irruptive insects will undergo population transitions and under what circumstances they

473 are most amenable to intervention if desired. 


\section{Acknowledgments}

475 This investigation comprised a very large and complex multi-year field study that would not

476 have been possible without invaluable contributions from Douglas Linton, Tony Ibaraki, Greg

477 Smith, Andrew Copeland, Dion Manastyrski and Fred Davis. Funding was generously provided

478 to ALC by Natural Resources Canada - Mountain Pine Beetle Initiative. Further support was

479 provided by the University of Wisconsin- Madison College of Agricultural and Life Sciences,

480 Graduate School and Vilas-Sorenson Professorship. We thank Anthony R. Ives, (UW-Madison)

481 and Guillherme Ludwig (University of Campinas) for helpful conversations on analyzing point

482 patterns.

483

484 Declarations

485 We declare no conflicts of interest. 


\section{References}

487

Allen CD, Breshears DD, McDowell NG (2015) On underestimation of global vulnerability to tree mortality and forest die-off from hotter drought in the Anthropocene. Ecosphere 6:art129. https://doi.org/10.1890/ES15-00203.1

Anderegg WRL, Hicke JA, Fisher RA, et al (2015) Tree mortality from drought, insects, and their interactions in a changing climate. New Phytologist 208:674-683. https://doi.org/10.1111/nph.13477

Aukema BH, Carroll AL, Zheng Y, et al (2008) Movement of outbreak populations of mountain pine beetle: Influences of spatiotemporal patterns and climate. Ecography 31:348-358. https://doi.org/10.1111/j.0906-7590.2007.05453.x

Aukema BH, Carroll AL, Zhu J, et al (2006) Landscape level analysis of mountain pine beetle in British Columbia, Canada: spatiotemporal development and spatial synchrony within the present outbreak. Ecography 29:427-441. https://doi.org/10.1111/j.2006.09067590.04445.x

Ayres MP, Lombardero MJ (2000) Assessing the consequences of global change for forest disturbance from herbivores and pathogens. Science of the Total Environment 262:263286. https://doi.org/10.1016/S0048-9697(00)00528-3

Bentz BJ (1996) Localized Spatial and Temporal Attack Dynamics of the Mountain Pine Beetle in Lodgepole Pine. U.S. Department of Agriculture, Forest Service, Intermountain Research Station

Berryman AA (1996) What causes population cycles of forest Lepidoptera? Trends in Ecology \& Evolution 11:28-32. https://doi.org/10.1016/0169-5347(96)81066-4

Berryman AA (1987) The Theory and Classification of Outbreaks. In: Insect Outbreaks. Elsevier, pp 3-30

Biedermann PHW, Müller J, Grégoire J-CC, et al (2019) Bark Beetle Population Dynamics in the Anthropocene: Challenges and Solutions. Trends in Ecology \& Evolution xx:1-11. https://doi.org/10.1016/j.tree.2019.06.002

Bjornstad ON, Grenfell BT (2001) Noisy Clockwork: Time Series Analysis of Population Fluctuations in Animals. Science 293:638-643. https://doi.org/10.1126/science.1062226

Bleiker KP, O'Brien MR, Smith GD, Carroll AL (2014) Characterisation of attacks made by the mountain pine beetle (Coleoptera: Curculionidae) during its endemic population phase. Can Entomol 146:271-284. https://doi.org/10.4039/tce.2013.71 
Blomquist GJ, Figueroa-Teran R, Aw M, et al (2010) Pheromone production in bark beetles. Insect Biochemistry and Molecular Biology 40:699-712. https://doi.org/10.1016/j.ibmb.2010.07.013

Boone CK, Aukema BH, Bohlmann J, et al (2011) Efficacy of tree defense physiology varies with bark beetle population density: a basis for positive feedback in eruptive species. Canadian Journal of Forest Research 41:1174-1188. https://doi.org/10.1139/x11-041

Burke JL, Carroll AL (2017) Breeding matters: Natal experience influences population Statedependent host acceptance by an eruptive insect herbivore. PLoS ONE 12:1-16. https://doi.org/10.1371/journal.pone.0172448

Chang W-Y, Lantz VA, Hennigar CR, MacLean DA (2012) Benefit-cost analysis of spruce budworm (Choristoneura fumiferana Clem.) control: Incorporating market and nonmarket values. Journal of Environmental Management 93:104-112. https://doi.org/10.1016/j.jenvman.2011.08.022

Cobbold CA, Roland J, Lewis MA (2009) The impact of parasitoid emergence time on hostparasitoid population dynamics. Theoretical Population Biology 75:201-215. https://doi.org/10.1016/j.tpb.2009.02.004

Cooke BJ, Carroll AL (2017) Predicting the risk of mountain pine beetle spread to eastern pine forests: Considering uncertainty in uncertain times. Forest Ecology and Management 396:11-25. https://doi.org/10.1016/j.foreco.2017.04.008

Dwyer G, Dushoff J, Yee SH (2004) The combined effects of pathogens and predators on insect outbreaks. Nature 430:341-345. https://doi.org/10.1038/nature02569

Gitau CW, Bashford R, Carnegie AJ, Gurr GM (2013) A review of semiochemicals associated with bark beetle (Coleoptera: Curculionidae: Scolytinae) pests of coniferous trees: A focus on beetle interactions with other pests and their associates. Forest Ecology and Management 297:1-14. https://doi.org/10.1016/j.foreco.2013.02.019

Hart SJ, Veblen TT, Schneider D, Molotch NP (2017) Summer and winter drought drive the initiation and spread of spruce beetle outbreak. Ecology 98:2698-2707. https://doi.org/10.1002/ecy.1963

Hicke JA, Allen CD, Desai AR, et al (2012) Effects of biotic disturbances on forest carbon cycling in the United States and Canada. Global Change Biology 18:7-34. https://doi.org/10.1111/j.1365-2486.2011.02543.x

Hicke JA, Meddens AJH, Kolden CA (2016) Recent Tree Mortality in the Western United States from Bark Beetles and Forest Fires. Forest Science 62:141-153. https://doi.org/10.5849/forsci.15-086 
Jepsen JU, Hagen SB, Ims RA, Yoccoz NG (2008) Climate change and outbreaks of the geometrids Operophtera brumata and Epirrita autumnata in subarctic birch forest: evidence of a recent outbreak range expansion. Journal of Animal Ecology 77:257-264. https://doi.org/10.1111/j.1365-2656.2007.0

Kausrud K, Økland B, Skarpaas O, et al (2012) Population dynamics in changing environments: the case of an eruptive forest pest species. Biological Reviews 87:34-51. https://doi.org/10.1111/j.1469-185X.2011.00183.x

Kendall BE, Briggs CJ, Murdoch WW, et al (1999) Why Do Populations Cycle? A Synthesis of Statistical and Mechanistic Modeling Approaches. Ecology 80:1789-1805. https://doi.org/10.1890/0012-9658(1999)080[1789:WDPCAS]2.0.CO;2

Klutsch JG, Beam RD, Jacobi WR, Negrón JF (2014) Bark beetles and dwarf mistletoe interact to alter downed woody material, canopy structure, and stand characteristics in northern Colorado ponderosa pine. Forest Ecology and Management 315:63-71. https://doi.org/10.1016/j.foreco.2013.12.024

Kolb TE (2016) Observed and anticipated impacts of drought on forest insects and diseases in the United States. Forest Ecology and Management 14

Krause AM, Townsend PA, Lee Y, Raffa KF (2018) Predators and competitors of the mountain pine beetle Dendroctonus ponderosae (Coleoptera: Curculionidae) in stands of changing forest composition associated with elevation: Predators of mountain pine beetle at low densities. Agr Forest Entomol 20:402-413. https://doi.org/10.1111/afe.12272

Kurz WA, Dymond CC, Stinson G, et al (2008) Mountain pine beetle and forest carbon feedback to climate change. Nature 452:987-90. https://doi.org/10.1038/nature06777

Liebhold AM, Tobin PC (2008) Population Ecology of Insect Invasions and Their Management *. https://doi.org/10.1146/annurev.ento.52.110405.091401

Lindgren BS, Raffa KF (2013) Evolution of tree killing in bark beetles (Coleoptera: Curculionidae): trade-offs between the maddening crowds and a sticky situation. Can Entomol 145:471-495. https://doi.org/10.4039/tce.2013.27

Logan JA, Régnière J, Powell JA (2003) Assessing the impacts of global warming on forest pest dynamics. Frontiers in Ecology and the Environment 1:130-137. https://doi.org/10.1890/1540-9295(2003)001[0130:ATIOGW]2.0.CO;2

Logan JA, White P, Bentz BJ, Powell JA (1998) Model Analysis of Spatial Patterns in Mountain Pine Beetle Outbreaks. Theoretical Population Biology 53:236-255. https://doi.org/10.1006/tpbi.1997.1350 
Marini L, Ayres MP, Battisti A, Faccoli M (2012) Climate affects severity and altitudinal distribution of outbreaks in an eruptive bark beetle. Climatic Change 115:327-341. https://doi.org/10.1007/s10584-012-0463-z

McDowell NG, Allen CD, Anderson-Teixeira K, et al (2020) Pervasive shifts in forest dynamics in a changing world. Science 368:eaaz9463. https://doi.org/10.1126/science.aaz9463

Nebeker TE, Tisdale RA, Schmitz RF, Hobson KR (1995) Chemical and nutritional status of dwarf mistletoe, Armillaria root rot, and Comandra blister rust infected trees which may influence tree susceptibility to bark beetle attack. Can J Bot 73:360-369. https://doi.org/10.1139/b95-037

Økland B, Berryman A (2004) Resource dynamic plays a key role in regional fluctuations of the spruce bark beetles Ips typographus. Agricultural \& Forest Entomology 6:141-146. https://doi.org/10.1111/j.1461-9555.2004.00214.x

Økland B, Bjørnstad ON (2006) A Resource-Depletion Model of Forest Insect Outbreaks. Ecology 87:283-290. https://doi.org/10.1890/05-0135

Peltonen M, Liebhold AM, Bjørnstad ON, Williams DW (2002) Spatial synchrony in forest insect outbreaks: Roles of regional stochasticity and dispersal. Ecology 83:3120-3129. https://doi.org/10.1890/0012-9658(2002)083[3120:SSIFIO]2.0.CO;2

Powell EN, Townsend PA, Raffa KF (2012) Wildfire provides refuge from local extinction but is an unlikely driver of outbreaks by mountain pine beetle. Ecological Monographs 82:6984. https://doi.org/10.1890/11-0607.1

Powers JS, Sollins P, Harmon ME, Jones JA (1999) Plant-pest interactions in time and space: A Douglas-fir bark beetle outbreak as a case study. Landscape Ecology 14:105-120. https://doi.org/10.1023/A:1008017711917

Preisler HK, Hicke JA, Ager AA, Hayes JL (2012) Climate and weather influences on spatial temporal patterns of mountain pine beetle populations in Washington and Oregon. Ecology 93:2421-2434. https://doi.org/10.1890/11-1412.1

Raffa KF, Aukema BH, Bentz BJ, et al (2008) Cross-scale Drivers of Natural Disturbances Prone to Anthropogenic Amplification: The Dynamics of Bark Beetle Eruptions. BioScience 58:501-517. https://doi.org/10.1641/B580607

Raffa KF, Aukema BH, Erbilgin N, et al (2005) Interactions among conifer terpenoids and bark beetles across multiple levels of scale: an attempt to understand links between population patterns and physiological processes. In: Romeo JT (ed) Chemical Ecology and Phytochemistry of Forest Ecosystems. pp 79-118 
618

619

620

621

622

623

624

625

626

627

628

629

630

631

632

633

634

635

636

637

638

639

640

641

642

643

644

645

646

647

648

649

650

651

Rankin LJ, Borden JH (1991) Competitive interactions between the mountain pine beetle and the pine engraver in lodgepole pine. Can J For Res 21:1029-1036. https://doi.org/10.1139/x91-141

Roffey J, Popov G (1968) Environmental and Behavioural Processes in a Desert Locust Outbreak. Nature 219:446-450. https://doi.org/10.1038/219446a0

Royama T (1992) Basic properties and structure of population processes. In: Royama T (ed) Analytical Population Dynamics. Springer Netherlands, Dordrecht, pp 3-46

Safranyik L, Carroll AL (2006) The biology and epidemiology of the mountain pine beetle in lodgepole pine forests. In: The Mountain Pine Beetle: A Synthesis of Its Biology, Management and Impacts on Lodgepole Pine. Natural Resources Canada, Candian Forest Service, Victoria, BC, Canada, pp 3-66

Safranyik L, Carroll AL, Regniere J, et al (2010) Potential for range expansion of mountain pine beetle into the boreal forest of North America. Canadian Entomologist 142:415-442. https://doi.org/10.4039/n08-CPA01

Safranyik L, Shore TL, Linton DA, Rankin LJ (eds) (1999) Effects of induced competitive interactions with secondary bark beetle species on the establishment and survival of mountain pine beetle broods in lodgepole pine. Canadian Forest Service, Pacific Forestry Centre, Victoria, B.C

Seidl R, Müller J, Hothorn T, et al (2016) Small beetle, large-scale drivers: How regional and landscape factors affect outbreaks of the European spruce bark beetle. Journal of Applied Ecology 53:530-540. https://doi.org/10.1111/1365-2664.12540

Seidl R, Schelhaas M-J, Rammer W, Verkerk PJ (2015) Increasing forest disturbances in Europe and their impact on carbon storage. 12

Seidl R, Thom D, Kautz M, et al (2017) Forest disturbances under climate change. Nature Climate Change 7:395-402. https://doi.org/10.1038/nclimate3303

Smith GD, Carroll AL, Lindgren BS (2011) Facilitation in bark beetles: endemic mountain pine beetle gets a helping hand. Agricultural and Forest Entomology 13:37-43. https://doi.org/10.1111/j.1461-9563.2010.00499.x

Sommerfeld A, Senf C, Buma B, et al (2018) Patterns and drivers of recent disturbances across the temperate forest biome. Nature Communications 9:. https://doi.org/10.1038/s41467018-06788-9

Turchin P (1999) Dynamical Role of Predators in Population Cycles of a Forest Insect: An Experimental Test. Science 285:1068-1071. https://doi.org/10.1126/science.285.5430.1068 
652 Wallin KF, Raffa KF (2004) Feedback between Individual Host Selection Behavior and 653 Population Dynamics in an Eruptive Herbivore Author ( s ): Kimberly F. Wallin and Kenneth F . Raffa Published by : Wiley on behalf of the Ecological Society of America

656 Weed AS, Ayres MP, Hicke JA (2013) Consequences of climate change for biotic disturbances 657 in North American forests. Ecological Monographs 83:441-470

658 Williams DW, Liebhold AM (2006) Herbivorous Insects and Global Change: Potential Changes 659 in the Spatial Distribution of Forest Defoliator Outbreaks. Journal of Biogeography $660 \quad 22: 665$. https://doi.org/10.2307/2845968

661 Williams DW, Liebhold AM (2002) Climate change and the outbreak ranges of two North 662 American bark beetles. Agricultural and Forest Entomology 4:87-99.

663 https://doi.org/10.1046/j.1461-9563.2002.00124.x 


\section{Figure Captions}

666 Figure 1: Location of sites within British Columbia and mensurational characteristics $( \pm \mathrm{SE}$

667 when noted). DBH corresponds to diameter at breast height, and \%LPP to the percent of

668 lodgepole pine in a given stand.

669 Figure 2: Density dependent relationships between the stand-scale proportion of attacked trees

670 with prior stressors (A-C) and the tree-scale probability an attacked tree contains a prior stressor

671 (D-F) for three beetle guilds, the threshold limited mountain pine beetle (A,D); pulse-driven Ips

672 pini $(\mathrm{B}, \mathrm{E})$, and lower-stem beetles $(\mathrm{C}, \mathrm{F})$. Points in all panels correspond to the proportion of

673 attacked trees with prior stressors per stand. Colors denote beetle species. A detailed list of prior

674 stressors is provided in Supplemental Table 1.

675 Figure 3: Relationships between A) diameter at breast height; B) 5-year mean annual increment;

676 and C) phloem thickness vs. the number of attacked trees/ha; and D) the characteristics

677 associated with trees attacked by each guild. Colors denote species. Lines (A-C) are fit with

678 least-squares and only shown for significant relationships $(\alpha=0.05)$. Points (D) correspond to

679 principal components analysis of trees attacked by each guild. Screeplots are provided in

680 Supplemental Figure 1.

681 Figure 4: Spatial dynamics of trees attacked by mountain pine beetle from 1999-2005, separated

682 into A) those stands where patterns of attacked trees shifted from random to aggregated; and B)

683 those stands were transitions either did not occur (stands D \& G), or presumably occurred

684 because of immigrating beetles (Carrol et al. 2006). Points correspond to each attacked tree and 685 colors denote beetle species. Observed L(r)-r functions are provided for each year/stand/guild in

686 Supplemental Figure 3. 
687 Figure 5: Dynamics of spatial aggregation as a function of increasing population size, depicting 688 our interpretation of each observed L(r)-r function (Supplemental Figure 3). Points correspond to 689 each year-stand combination and colors denote species. Shapes denote our confidence in the 690 interpretation where $\mathrm{X}$ denotes point patterns with too few observations to interpret, open circles 691 denote point patterns where there was not significant aggregation, circles with crosses denote 692 point patterns that were significant, but barely, and filled circles denotes point patterns where 693 there was significant evidence of aggregation. The grey vertical box denotes the proposed 694 aggregation threshold. Since our interpretations may be construed as subjective, we provide an 695 alternative nearest-neighbor approach in Supplemental Figure 4.

696 Figure 6: Conditional spatial correlation of tree size at each stand. Curves are fit with all species 697 since the conditional mean behaves better with equally spaced distances and the curve for stand 698 B corresponds to $1999-2003$ since we are primarily interested in the initial aggregation phase. 


\section{Supplemental Figures}

702 Figure 1: Screeplots for principal components analysis, depicting A) the variability explained by

703 each dimension; and the factors contributing to the B) $1^{\text {st }}$, C) $2^{\text {nd }}$, and D) $3^{\text {rd }}$ dimensions.

704 Figure 2: Walkthrough of hypothesis testing process given a small $(200 \times 200 \mathrm{~m})$ window from

705 stand $\mathrm{A}$ in 2005. The example is testing whether the distribution of trees attacked by mountain

706 pine beetle is more (aggregation) or less (inhibition) spatially correlated than randomly

707 distributed points (Poisson) based on the underlying joint density of beetle attacks. Point color

708 denotes bark beetle guild for threshold limited (i.e., mountain pine beetle; black) and lower-stem

709 (yellow). Gradient color denotes intensity of the joint density and is depicted on different scales

710 for each null hypothesis. Scales are not shown because the relative intensity is more important

711 than the realized values.

712 Figure 3: Alternative hypothesis testing for the spatial configuration of attacked trees based on

713 A) a nearest-neighbor approach (Clark Evan's Aggregation Index) and B) how our

714 interpretations of observed L(r)-r functions compares. Colors denote bark beetle guild. Shapes in

715 A correspond to significance assessed at the $\alpha=0.01$ level where filled circles denote significant

716 and open circles denote not significant. Shapes in $\mathbf{B}$ correspond to our interpretation of the

717 observed L(r)-r functions, where filled circles denote significant aggregation, circles with crosses

718 denote weak significant aggregation (i.e., the observed L(r)-r function barely exceeded the

719 significance bands), open circles denote no significant aggregation, and X's denote

720 stand/year/guild combinations where there were fewer than 5 attacked trees.

721 


\section{Supplemental Tables}

723 Supplemental Table 1: Criteria used to estimate the number of years since initial complete (A)

724 or partial (B) attacks by bole-infesting bark beetles on lodgepole pine trees. Adopted from Carrol

725 et al. (2006).

726 Supplemental Table 2: Distribution of prior stressors A) in each stand, and B) the number of

727 trees with at least $0,1,2,3$, or 4 stressors.

728 Supplemental Table 3: Observed L(r)-r functions for each guild/stand/year combination.

729 Patterns not shown contained less than five attacked trees. Panels for each point pattern

730 correspond to different null hypotheses of the underlying spatial distribution of available host

731 trees. We provide our interpretation of whether each pattern exhibits significant aggregation or

732 inhibition in the right-hand columns. 
Figures

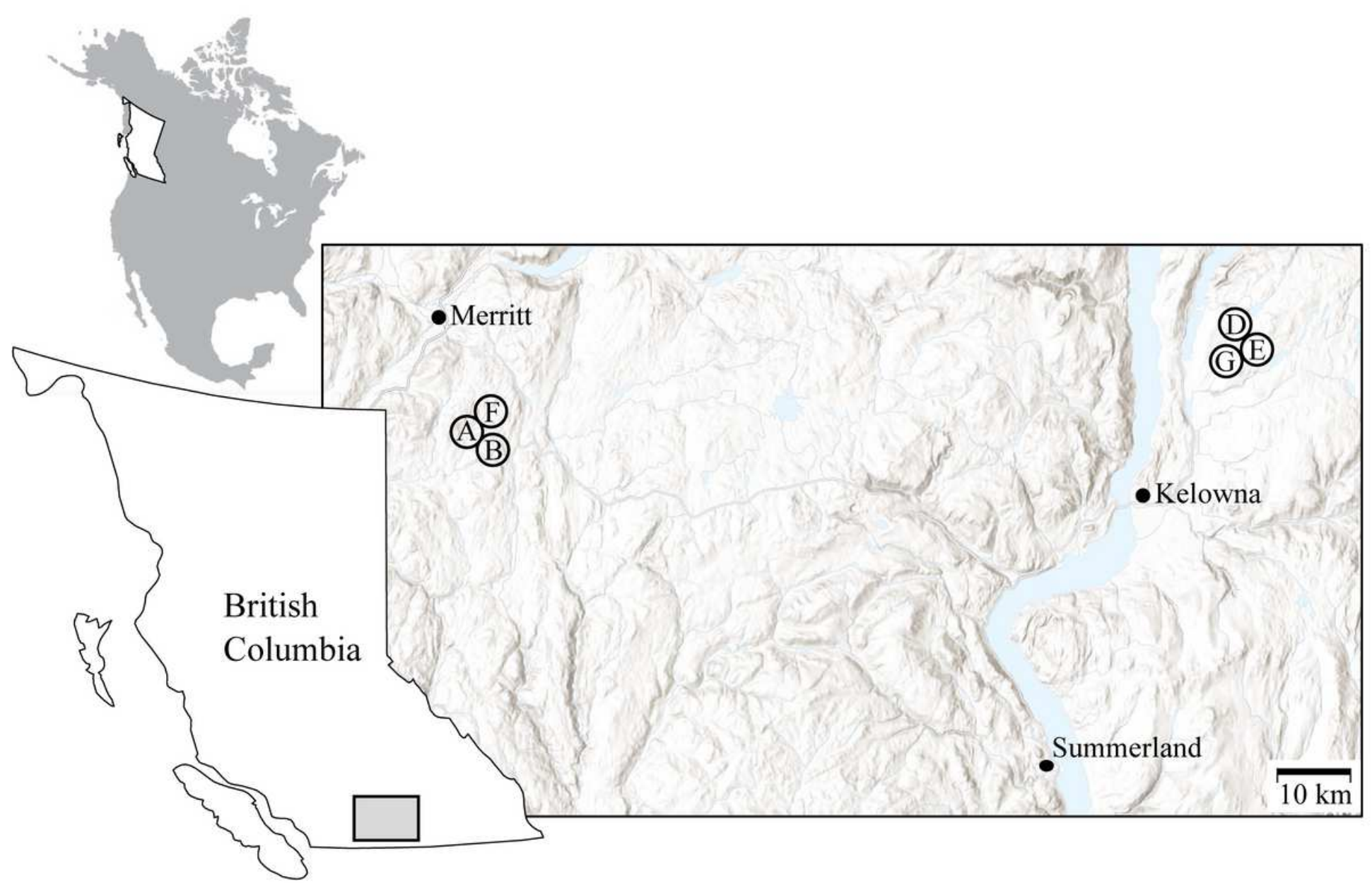

\begin{tabular}{lrrrrrrr} 
Stand & Elevation $(\mathrm{m})$ & Area $(\mathrm{ha})$ & Age $(\mathrm{yrs} \pm \mathrm{SE})$ & Density $($ trees $/ \mathrm{ha} \pm \mathrm{SE})$ & Basal Area $\left(\mathrm{m}^{2} / \mathrm{ha} \pm \mathrm{SE}\right)$ & $\mathrm{DBH}(\mathrm{cm} \pm \mathrm{SE})$ & $\% \mathrm{LPP}$ \\
\hline $\mathrm{A}$ & 1163 & 16.7 & $110.5(1.52)$ & $1265(252.9)$ & $41.5(6.9)$ & $22.8(0.61)$ & 92.5 \\
$\mathrm{~B}$ & 1121 & 17.6 & $116.5(1.18)$ & $1273(190.4)$ & $43.9(6.7)$ & $24.1(0.58)$ & 94.5 \\
$\mathrm{D}$ & 1384 & 13.0 & $119.2(1.97)$ & $1325(153.2)$ & $37.0(4.1)$ & $21.5(0.63)$ & 90.4 \\
$\mathrm{E}$ & 1346 & 7.9 & $90.7(2.56)$ & $1257(249.6)$ & $37.6(5.9)$ & $21.2(0.91)$ & 90.6 \\
$\mathrm{~F}$ & 1204 & 11.9 & $148.9(1.55)$ & $807(148.4)$ & $30.6(5.3)$ & $28.2(0.80)$ & 80.1 \\
$\mathrm{G}$ & 1426 & 14.9 & $108.6(0.58)$ & $1424(115.0)$ & $49.6(4.4)$ & $22.5(0.43)$ & 94.2
\end{tabular}

\section{Figure 1}

Location of sites within British Columbia and mensurational characteristics ( \pm SE when noted). DBH corresponds to diameter at breast height, and \%LPP to the percent of lodgepole pine in a given stand. 

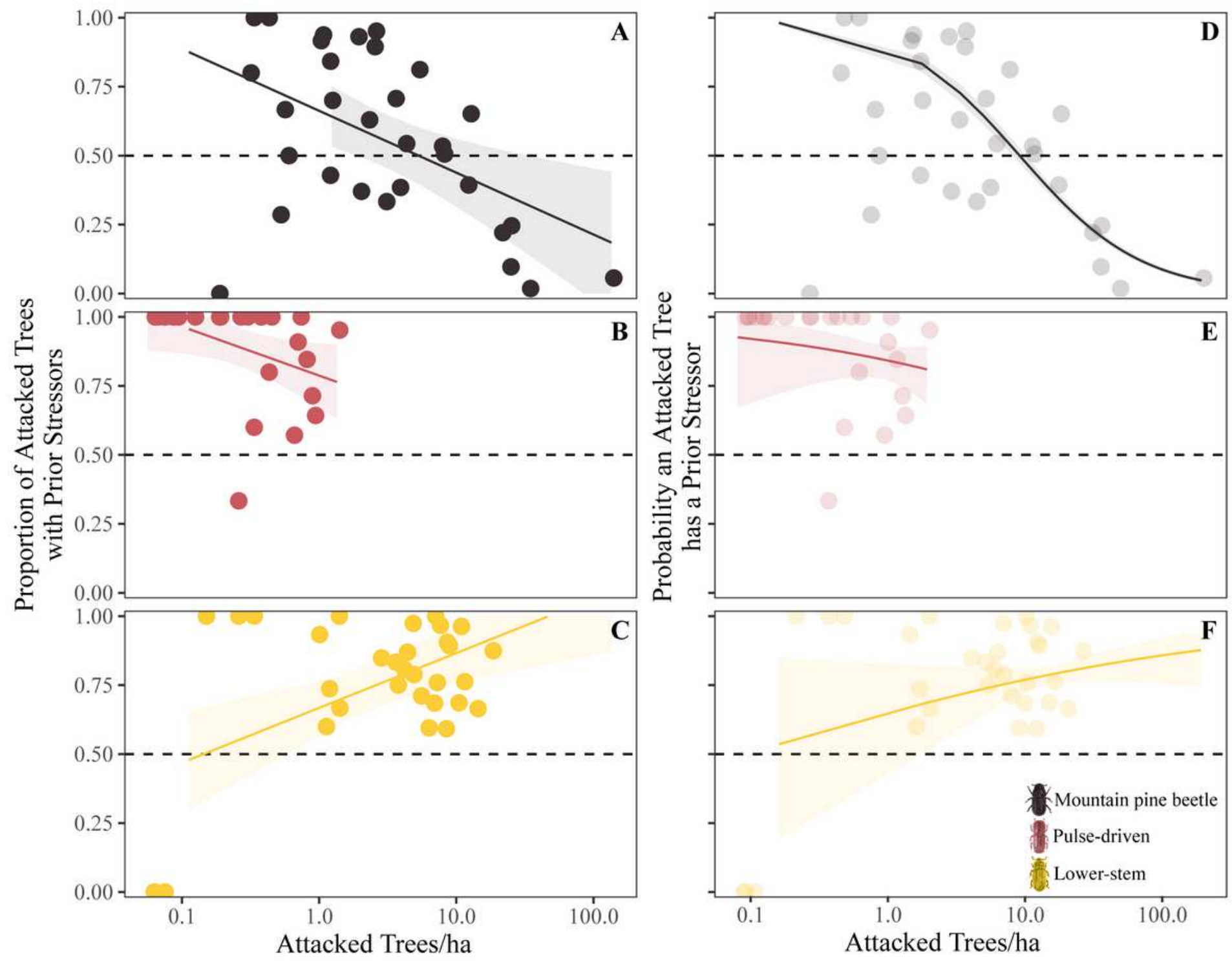

Figure 2

Density dependent relationships between the stand-scale proportion of attacked trees with prior stressors $(A-C)$ and the tree-scale probability an attacked tree contains a prior stressor (D-F) for three beetle guilds, the threshold limited mountain pine beetle $(A, D)$; pulse-driven Ips pini $(B, E)$, and lower-stem beetles $(C, F)$. Points in all panels correspond to the proportion of attacked trees with prior stressors per stand. Colors denote beetle species. A detailed list of prior stressors is provided in Supplemental Table 1. 

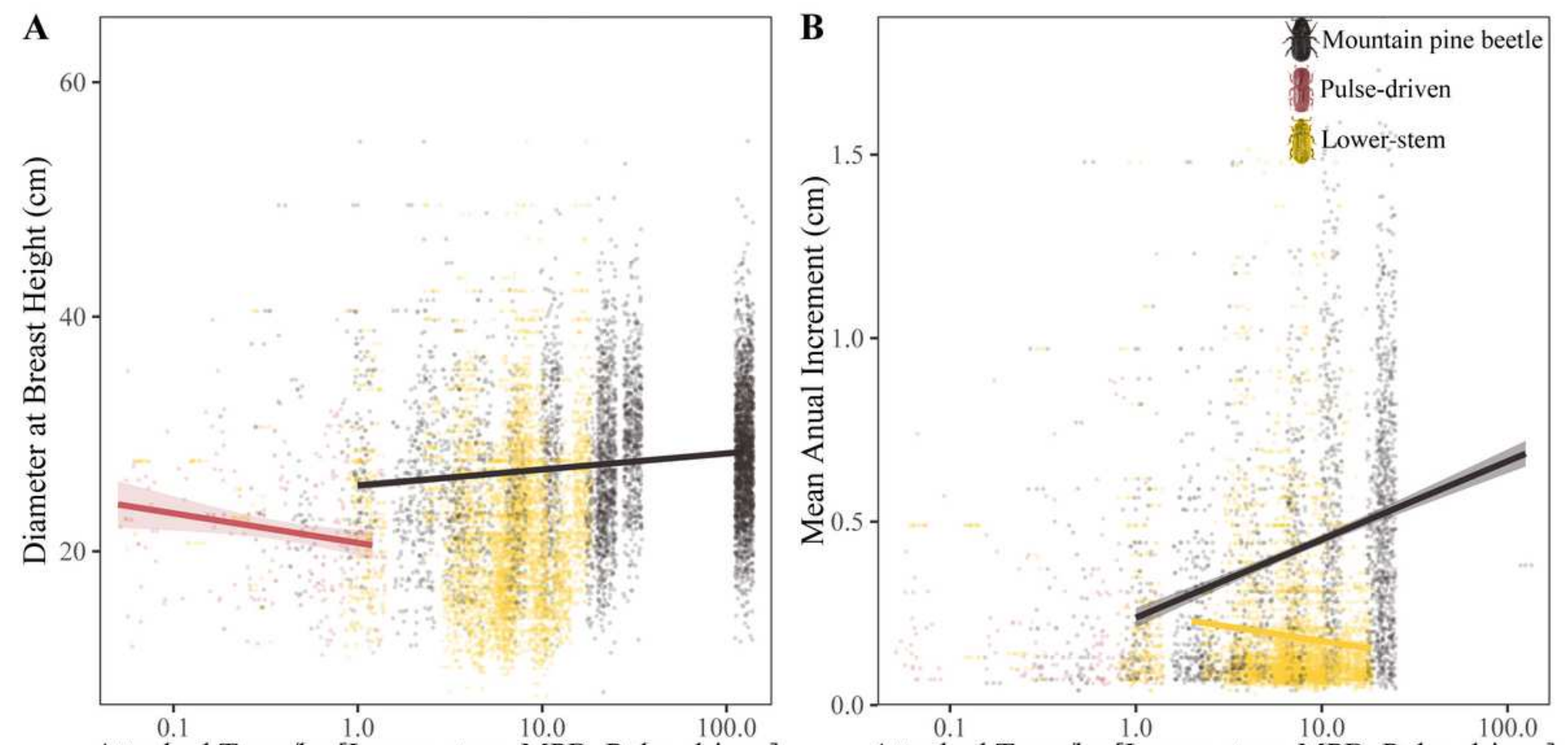

Attacked Trees/ha [Lower-stem, MPB, Pulse-driven]
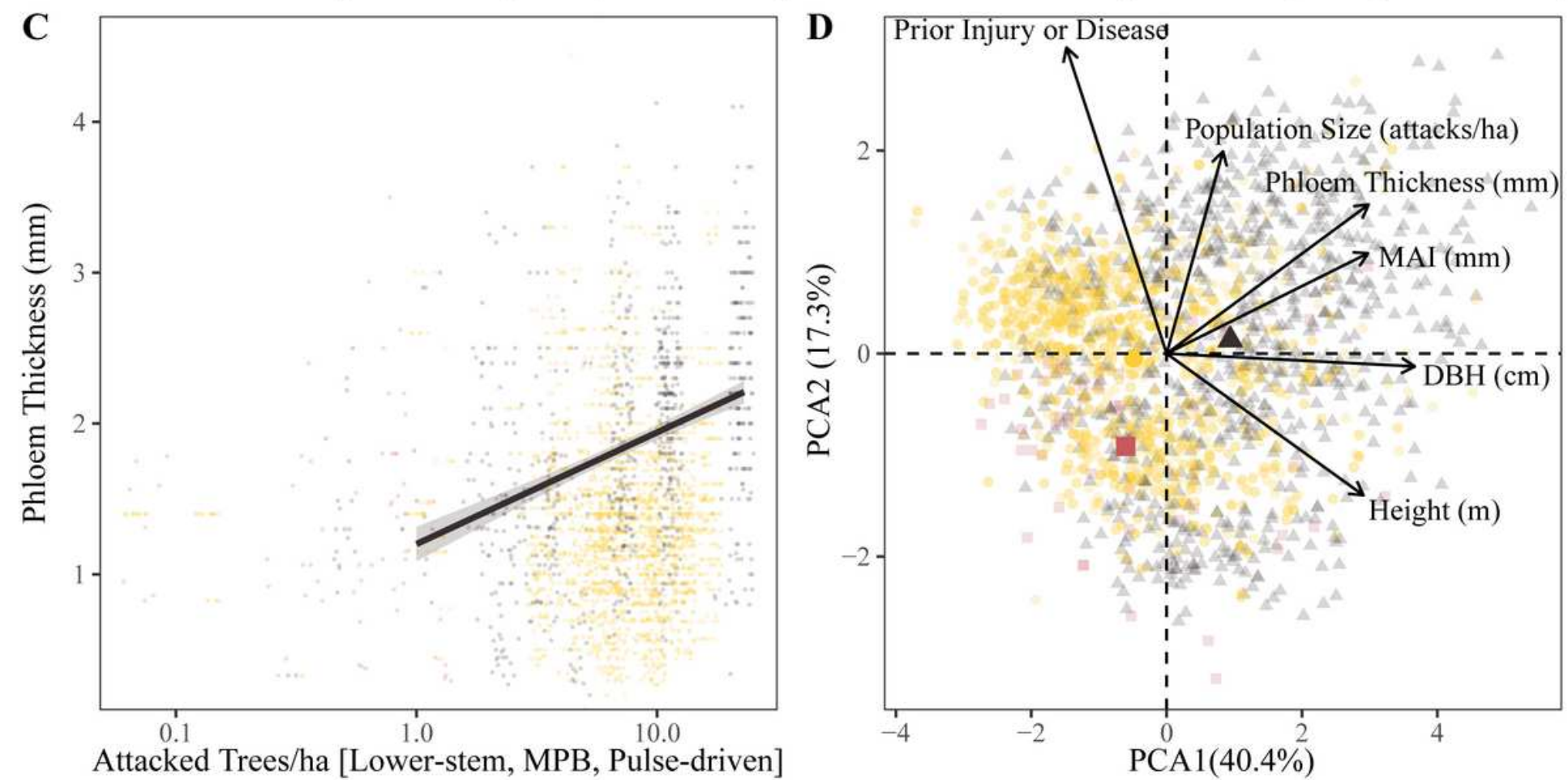

\section{Figure 3}

Relationships between A) diameter at breast height; B) 5-year mean annual increment; and C) phloem thickness vs. the number of attacked trees/ha; and D) the characteristics associated with trees attacked by each guild. Colors denote species. Lines (A-C) are fit with least-squares and only shown for significant relationships $(a=0.05)$. Points $(D)$ correspond to principal components analysis of trees attacked by each guild. Screeplots are provided in Supplemental Figure 1. 
A
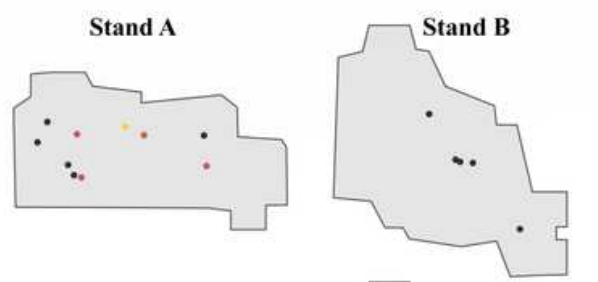

Stand F

Mountain pine beetle

8) Pulse-driven

Lower-stem

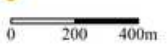

2000
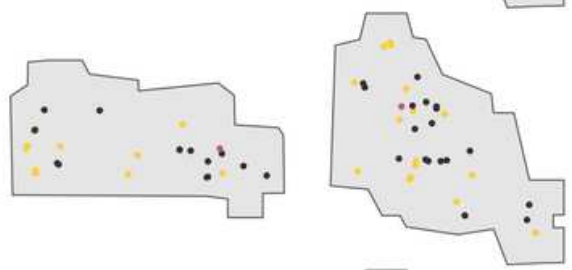

2001
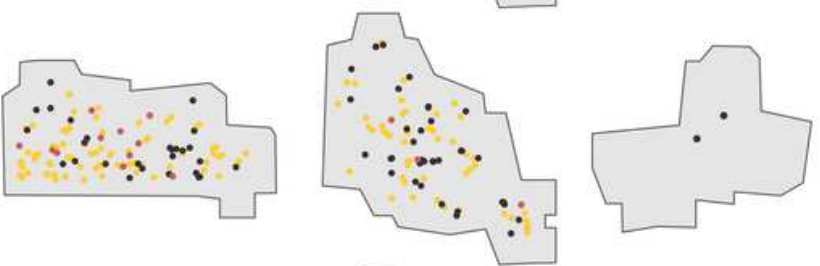

2002
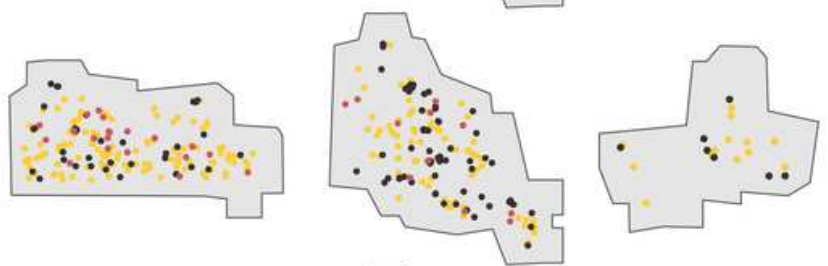

2003
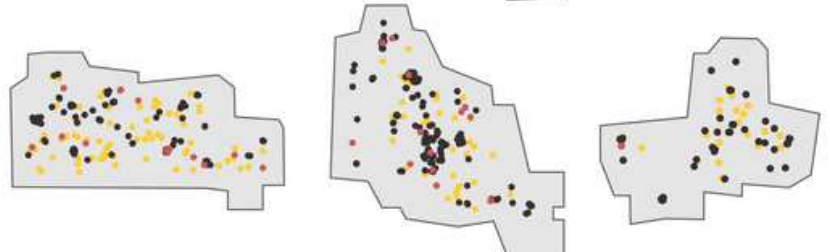

2004
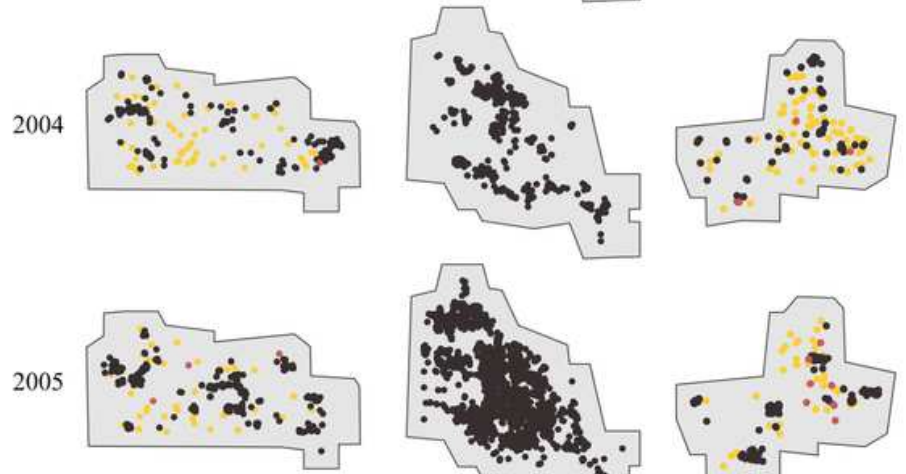

B
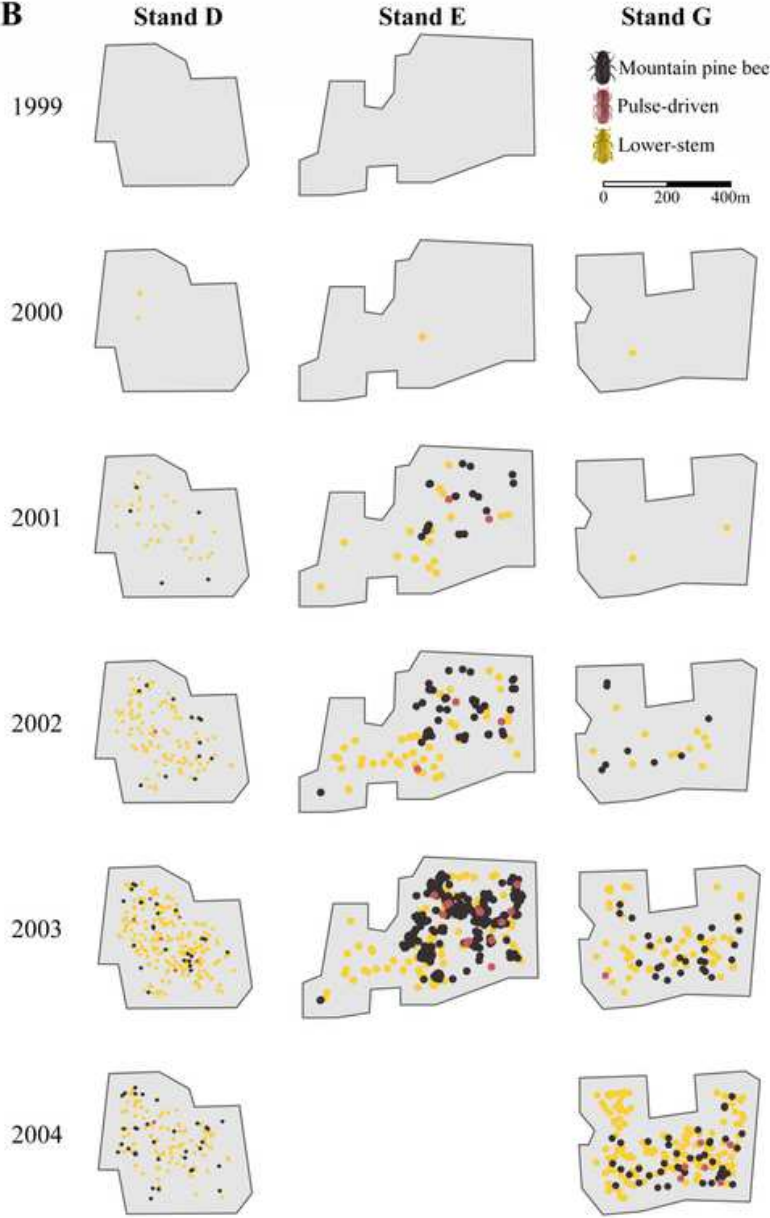

2005
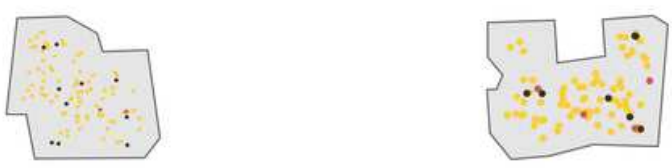

\section{Figure 4}

Spatial dynamics of trees attacked by mountain pine beetle from 1999-2005, separated into A) those stands where patterns of attacked trees shifted from random to aggregated; and B) those stands were transitions either did not occur (stands $D \& G$ ), or presumably occurred because of immigrating beetles (Carrol et al. 2006). Points correspond to each attacked tree and 685 colors denote beetle species. Observed L(r)-r functions are provided for each year/stand/guild in Supplemental Figure 3. 


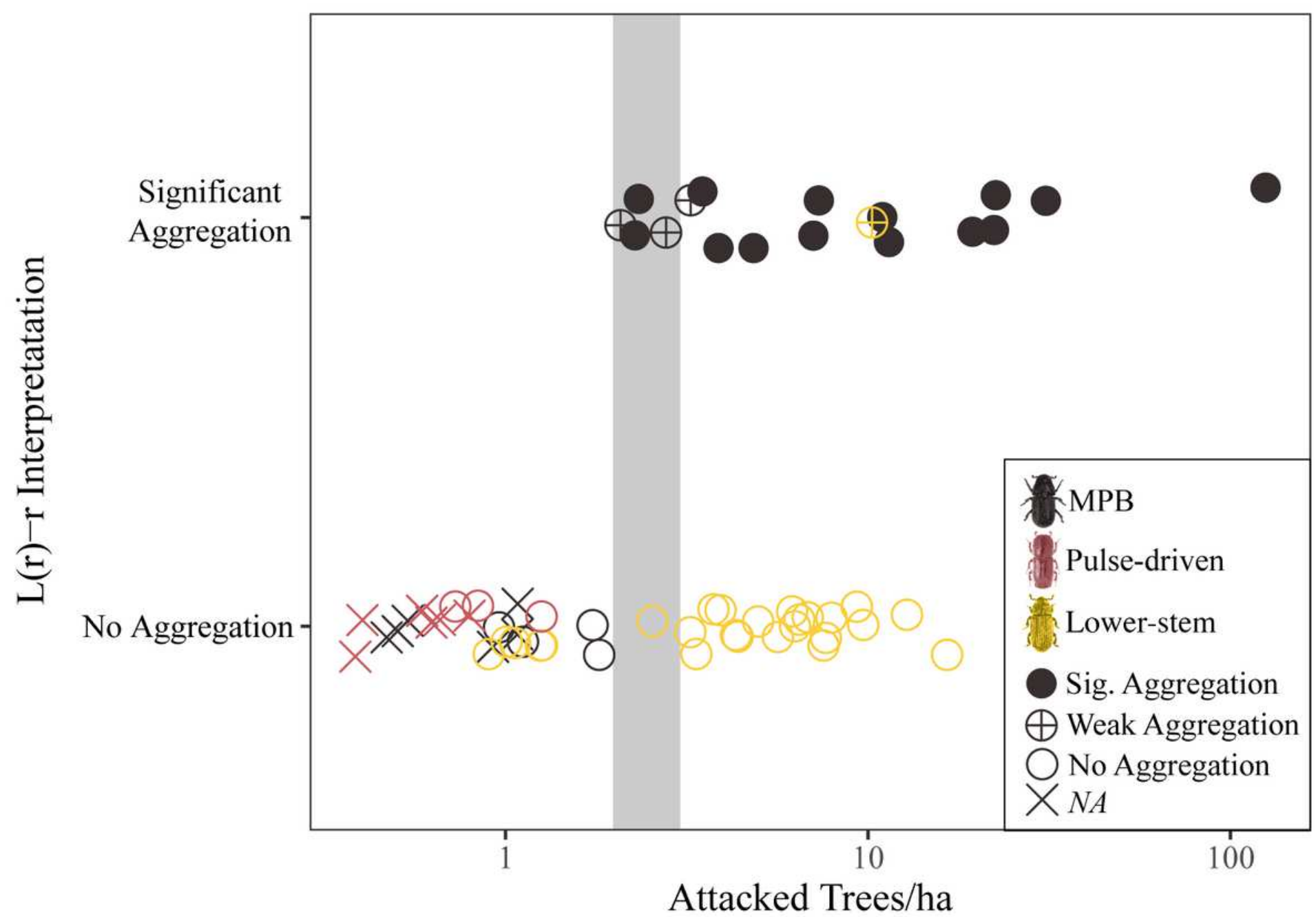

\section{Figure 5}

Dynamics of spatial aggregation as a function of i 687 ncreasing population size, depicting our interpretation of each observed L(r)-r function (Supplemental Figure 3). Points correspond to each yearstand combination and colors denote species. Shapes denote our confidence in the interpretation where $X$ denotes point patterns with too few observations to interpret, open circles denote point patterns where there was not significant aggregation, circles with crosses denote point patterns that were significant, but barely, and filled circles denotes point patterns where there was significant evidence of aggregation. The grey vertical box denotes the proposed aggregation threshold. Since our interpretations may be construed as subjective, we provide an alternative nearest-neighbor approach in Supplemental Figure 4. 

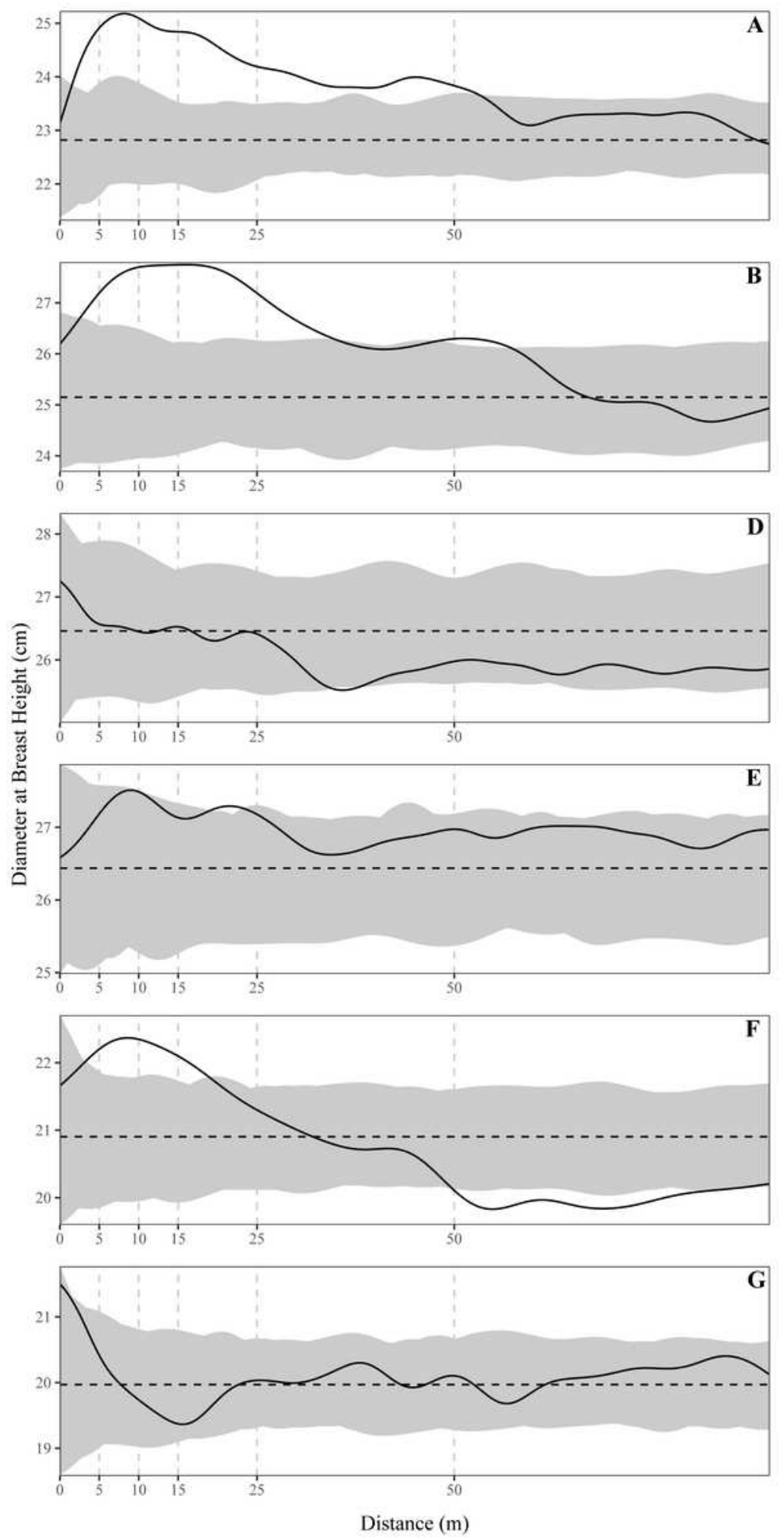

\section{Figure 6}

Conditional spatial correlation of tree size at each stand. Curves are fit with all species since the conditional mean behaves better with equally spaced distances and the curve for stand B corresponds to 1999-2003 since we are primarily interested in the initial aggregation phase.

\section{Supplementary Files}


This is a list of supplementary files associated with this preprint. Click to download.

- SF101.png

- SF201.png

- SF301.png

- ST1.docx

- ST2.docx

- ST3.docx 